\title{
openheart Prevalence and prognostic impact of kidney disease on heart failure patients
}

\author{
Ida Löfman, ${ }^{1,2}$ Karolina Szummer, ${ }^{1,2}$ Inger Hagerman,, ${ }^{1,2}$ Ulf Dahlström, ${ }^{3}$ \\ Lars H Lund, ${ }^{4,5}$ Tomas Jernberg ${ }^{1,2}$
}

To cite: Löfman I, Szummer K, Hagerman I, et al. Prevalence and prognostic impact of kidney disease on heart failure patients. Open Heart 2016;3: e000324. doi:10.1136/ openhrt-2015-000324

- Additional material is available. To view please visit the journal (http://dx.doi.org/ 10.1136/openhrt-2015000324)

Received 16 August 2015 Revised 14 October 2015 Accepted 5 December 2015

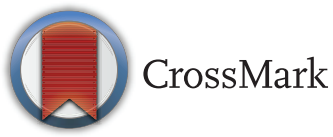

${ }^{1}$ Department of Medicine, Section of Cardiology, Huddinge, Sweden ${ }^{2}$ Karolinska Institutet, Karolinska University Hospital, Stockholm, Sweden ${ }^{3}$ Department of Cardiology, Department of Medical and Health Sciences, Linköping University Hospital, Linköping, Sweden

${ }^{4}$ Department of Medicine, Section of Cardiology, Solna, Sweden

${ }^{5}$ Karolinska Institutet, Karolinska University Hospital, Stockholm, Sweden

Correspondence to Dr Ida Löfman; ida.haugenlofman@karolinska.se

\section{ABSTRACT}

Objectives: The aim was to determine the prevalence of different degrees of kidney dysfunction and to examine their association with short-term and longterm outcomes in a large unselected contemporary heart failure population and some of its subgroups. We examined to what extent the different cardiac conditions and their severity contribute to the prognostic value of kidney dysfunction in heart failure. Design: We studied 47716 patients in the Swedish Heart Failure Registry. Patients were divided into five renal function strata based on estimated glomerular filtration rate (eGFR) using the Chronic Kidney Disease Epidemiology Collaboration equation. The adjusted association between kidney function and outcome was examined by Cox regression.

Results: $51 \%$ of the patients had eGFR $<60 \mathrm{~mL} / \mathrm{min} /$ $1.73 \mathrm{~m}^{2}$ and $11 \%$ had eGFR $<30$. There was increasing mortality with decreasing kidney function regardless of age, presence of diabetes, New York Heart Association NYHA class, duration of heart failure and haemoglobin levels. The risk $\mathrm{HR}(95 \% \mathrm{Cl})$ persisted after adjusting for differences in baseline characteristics, severity of heart disease, and medical treatment: eGFR 60-89: 0.86 (0.79 to 0.95); eGFR 30-59: 1.13 (1.03 to 1.24 ); eGFR 15-29: 1.85 (1.67 to 2.07); and eGFR <15: 2.96 ([2.53 to -3.47$)]$, compared with $\mathrm{eGFR} \geq 90$.

Conclusions: Kidney dysfunction is common and strongly associated with short-term and long-term outcomes in patients with heart failure. This strong association was evident in all age groups, regardless of NYHA class, duration of heart failure, haemoglobin level, and presence/absence of diabetes mellitus. After adjusting for differences in baseline data, aetiology and severity of heart disease and treatment, the strong association remained.

\section{INTRODUCTION}

Heart failure is a serious condition with high mortality despite all modern treatment. ${ }^{1}$ Many factors contribute to the poor outcome in heart failure. ${ }^{2}$ Kidney dysfunction occurs in acute and chronic heart failure, and is associated with reduced survival. ${ }^{3}$ Over the years, our knowledge of the interaction between the heart and the kidney has increased, and parts of the pathophysiological background for the

\section{KEY QUESTIONS}

What is already known about this subject?

- Kidney failure, a known comorbidity in heart failure, is a part of the cardiorenal syndrome and associated with reduced survival.

What this study adds?

- In the study of the whole spectrum of reduced kidney function in a large unselected heart failure population and examination of the prognostic value of kidney dysfunction in important subgroups, we found that there is strong association between kidney dysfunction and outcomes in all age groups, regardless of New York Heart Association (NYHA) class, duration of heart failure, haemoglobin level and presence or absence of diabetes mellitus. This strong association remains even after adjustment for confounders, aetiology, and severity of heart disease and its treatment.

How this might impact on clinical practice?

- A simple measure of renal function in patients with heart failure will, adjusted or unadjusted, regardless of age group, presence of diabetes, NYHA class or anaemia, be an indicator of a patient's short and long-term prognosis. Our findings emphasise the importance of close follow-up and kidney preservation in patients with heart failure and kidney disease.

cardiorenal syndrome have been established. ${ }^{4}$ The heart and kidney function are closely linked together by haemodynamics, neurohormones and the sympathetic nervous system. $^{5}$

The cardiorenal syndrome is complex as heart failure and kidney disease share common risk factors and potentiate each other and other cardiovascular diseases. ${ }^{6}$ Most of the previous studies examining the prognostic value of kidney function in heart failure patients have been hampered mainly by inclusion of highly selected randomised controlled trial patients or small sample sizes, and have not been able to examine the whole spectrum of kidney dysfunction. ${ }^{78}$ In earlier large studies, the diagnoses of 
kidney disease have mainly been based on diagnostic codes, ${ }^{9}{ }^{10}$ or defined only by a certain level of creatinine. ${ }^{11}$ Most previous studies have examined short-term prognosis, whereas long-term follow-up has been uncommon. ${ }^{12}{ }^{13}$ Moreover, descriptions of the prognostic value of kidney dysfunction in important subgroups have been lacking.

The aim of this study was to determine the prevalence of different degrees of kidney dysfunction and to examine their association with short-term and longterm outcome in a large unselected contemporary heart failure population and some of its subgroups. We also wanted to examine to what extent different cardiac conditions and their severity contribute to the prognostic value of kidney dysfunction in heart failure patients.

\section{METHODS}

The Swedish heart failure register (SwedeHF) has been described in detail elsewhere. ${ }^{14}$ SwedeHF has since 2000 included patients with chronic heart failure and offers a unique possibility to study a large cohort of unselected heart failure patients.

It is a web-based national quality register including unselected heart failure patients, of whom $55 \%$ are registered during hospitalisation, while the remaining are registered in an outpatient setting at the hospital or in primary care. Inclusion criteria are clinician-judged heart failure and approximately 80 variables are recorded at discharge or during visit to a physician or healthcare team. The patients are informed of their participation in the SwedeHF and are allowed to opt out, but individual patient consent is not required. Uppsala Clinical Research Center (Uppsala, Sweden) is managing the database. Variables in the registry include baseline description of the patients, risk factors, history of heart disease, cardiac interventions, cardiac evaluation (ECG and echocardiogram), medication, and laboratory tests at discharge or at the outpatient visit. The protocol, registration form and annual report are available at http://www.rikssvikt.se

Only centres using creatinine measurements from methods that are traceable to isotope dilution mass spectroscopy standards were included. Glomerular filtration rate (eGFR) was estimated with the Chronic Kidney Disease Epidemiology Collaboration (CKD-EPI) equation. ${ }^{15}$ All patients were divided according to the current National Kidney Foundation Kidney Disease Outcomes Quality Initiative (KDIGO) recommendations into five renal function categories with eGFR $(\mathrm{mL} / \mathrm{min} /$ $\left.1.73 \mathrm{~m}^{2}\right)$ : higher or equal to 90 (eGFR $\geq 90$, normal function), eGFR higher or equal to 60 but below 90 (eGFR 60-89, mild dysfunction), eGFR higher or equal to 30 but below 60 (eGFR 30-59, moderate dysfunction), eGFR higher or equal to 15 but below 30 (eGFR 15-29, severe dysfunction) and eGFR less than 15 (eGFR $<15$, end stage renal disease (ESRD)). ${ }^{16}$ Owing to lack of data on albuminuria, these categories can only be considered as renal function strata and not chronic kidney disease (CKD) stages.

Information about mortality was obtained by linkage with the Swedish population registry, which includes the vital status of all Swedish citizens. The registry and the study conform to the declaration of Helsinki and the study was approved by the local ethical authority.

\section{Statistics}

Continuous variables are presented as median and IQR, and categorical variables are presented as counts and proportions $(\%)$. p Values for trends were assessed by Pearson $\chi^{2}$ for proportions and Kruskal-Wallis test for continuous variables. The index date was date of admission to hospital or date of outpatient visit, respectively. Crude survival was assessed and illustrated by Kaplan-Meier analyses. After graphically checking the model assumption of proportional hazard, univariable and multivariable Cox proportional hazard regression was used to examine the association between kidney function and outcome. In the first model, we adjusted for baseline variables possibly influencing both kidney dysfunction and outcome (age, gender, smoking, hypertension and diabetes). In the second model, we added variables related to the aetiology and severity of heart failure (heart failure $>6$ months, ischaemic heart disease, atrial fibrillation, valvular heart disease, dilated cardiomyopathy, previous revascularisation, previous valvular intervention, non-sinus rhythm in the electrocardiogram, heart rate, left ventricular ejection fraction (LVEF), New York Heart Association (NYHA) class, systolic blood pressure and haemoglobin level). In the third model, we also adjusted for the given treatment (ACE inhibitors, angiotensin-receptor blocker (ARB), $\beta$-blockers, aldosterone antagonists, statins and cardiac resynchronisation therapy (CRT)). To ensure linearity, the univariable association of different categorisations of the continuous variables and outcome was examined. Body mass index and heart rate were divided into quartiles before entry into the models, and age was divided into age/10 years. Haemoglobin $(\mathrm{Hb})$ and systolic blood pressure were divided in to four clinically-based categories: $\mathrm{Hb}>150 \mathrm{~g} / \mathrm{L}$ (as reference), $\mathrm{Hb} 120-149 \mathrm{~g} / \mathrm{L}, \mathrm{Hb}$ 90-119 g/L, and $\mathrm{Hb}<90 \mathrm{~g} / \mathrm{L}$; systolic blood pressure $>140 \mathrm{~mm} \mathrm{Hg}$ (as reference), $110-139 \mathrm{~mm} \mathrm{Hg}, \quad 90$ $109 \mathrm{~mm} \mathrm{Hg}$, and $<90 \mathrm{~mm} \mathrm{Hg}$.

\section{RESULTS}

From 11 May 2000 to 3 October 2013, a total of 88317 registrations occurred in SwedeHF. Only the first registration in the registry were included, and patients who lacked information on age, creatinine and confirmation that creatinine had been measured by a standardised method were excluded. Thus, 47716 patients were included in the analyses (figure 1). 


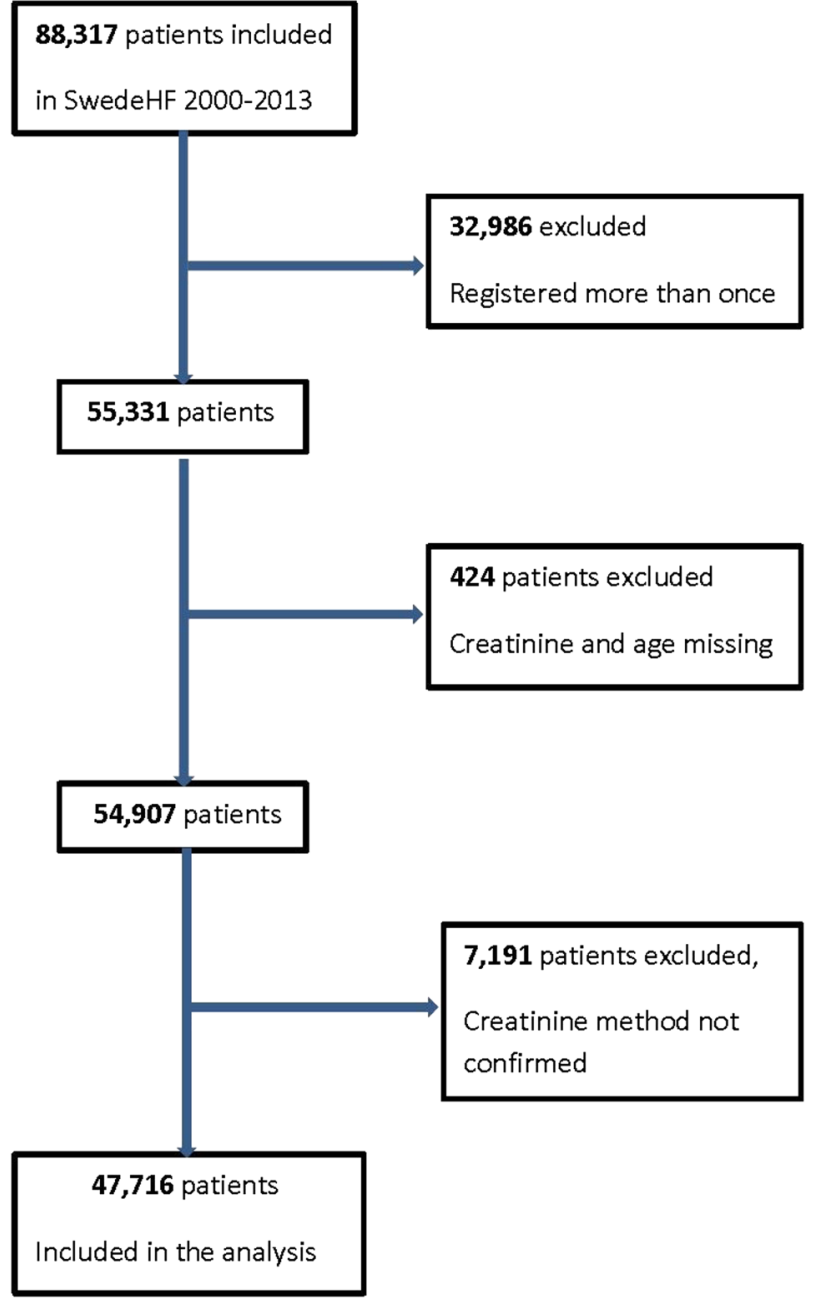

Figure 1 Patients included in the study. SwedeHF, Swedish heart failure register.

\section{Kidney function and heart disease}

A total of $24225(51 \%)$ patients had moderate kidney dysfunction (eGFR $<60 \mathrm{~mL} / \mathrm{min} / 1.73 \mathrm{~m}^{2}$ ) and 5065 $(11 \%)$ had a severe kidney dysfunction (eGFR $<30 \mathrm{~mL} /$ $\mathrm{min} / 1.73)$, of which $813(2 \%)$ was classified as ESRD $\left(\right.$ eGFR $<15 \mathrm{~mL} / \mathrm{min} / 1.73 \mathrm{~m}^{2}$; table 1$)$.

The median (IQR) age of the population was 77 (67-84) years with higher age in those with worse kidney dysfunction (table 1). Patients with lower kidney function were more often female with more hypertension and diabetes mellitus.

Also, patients with poor kidney function more often had ischaemic heart disease; however, they had a similar rate of previous revascularisation. Atrial fibrillation, stroke and valvular heart disease were more common in those with poor kidney function; however, they less often had dilated cardiomyopathy. Patients with lower kidney function more often had heart failure with a known duration of more than 6 months and were more often hospitalised at inclusion. Mildly symptomatic heart failure was more common in those with preserved kidney function and severe heart failure increased with worsened kidney function. Preserved ejection fraction was more common in those with low eGFR, whereas severe left ventricular systolic dysfunction (LVEF $<30 \%)$ was more common in those with preserved kidney function.

\section{Physical findings}

Regarding heart rate, blood pressure and body mass index, there were no major differences between the eGFR strata (table 2). Presence of left bundle branch block and QRS width did not differ between eGFR strata. The laboratory data showed that patients with low eGFR more often exhibited low haemoglobin and a high potassium level, and a markedly higher level of $\mathrm{N}$-terminal pro-brain natriuretic peptide (NT-proBNP).

\section{Treatment}

Patients with low kidney function were less likely to be treated with ACE inhibitor, $\beta$-blockers, and aldosterone blockade (table 2). If treated, they were also less likely to receive what was considered by guidelines to be the target dose of ACE inhibitor, ARB and $\beta$-blockers. Statins and anticoagulant treatment were used less often whereas aspirin was used more often in those with poor kidney function.

\section{Outcome}

Almost one-third of the hospitalised patients in the poorest eGFR strata $($ eGFR $<15)$ died during the actual hospitalisation. Half of all patients with ESRD (eGFR $<15)$ had died after 6 months and after 1 year, over $40 \%$ of those with severe kidney dysfunction (eGFR 15-29) and $60 \%$ of the patients with ESRD $(e G F R<15)$ had died (table 3).

There was an increasing mortality with decreasing kidney function regardless of age, presence of diabetes or not, NYHA class, and haemoglobin levels (figure 2A, B).

Although patients with heart failure for more than 6 months had a higher 1-year mortality than patients with heart failure of a shorter duration (25\% vs $16 \%)$, the prognosis was mainly dependent on the eGFR. One-year mortality in patients with normal kidney function was $7 \%$ for heart failure under 6 months versus $8 \%$ for heart failure over 6 months; in patients with eGFR< 15 , the 1 -year mortality was $61 \%$ versus $63 \%$ (see online supplementary table $\mathrm{S} 1$ ).

During long-term follow-up, the cumulative probability of death in 5 years was above $80 \%$ in patients with at least severe kidney dysfunction (eGFR $<30$ ), and $60 \%$ in those with moderate kidney dysfunction (eGFR 30-59; figure $3 \mathrm{~A}$ ). Even in the age group below 65 years, the prognosis was sinister with a $60 \%$ probability of death in 5 years for those with severe kidney dysfunction (figure 3B).

When adjusting for baseline variables possibly influencing both kidney dysfunction and outcome (age, gender, smoking, hypertension and diabetes) in model 1 , the association between eGFR and mortality was attenuated (table 3). When adding heart failure-related 
Table 1 Baseline characteristics

\begin{tabular}{|c|c|c|c|c|c|c|}
\hline Variable & $\begin{array}{l}\text { eGFR } \geq 90 \\
n=5251\end{array}$ & $\begin{array}{l}\text { eGFR } 60-89 \\
n=18240\end{array}$ & $\begin{array}{l}\text { eGFR } 30-59 \\
n=19160\end{array}$ & $\begin{array}{l}\text { eGFR 15-29 } \\
\mathrm{n}=4252\end{array}$ & $\begin{array}{l}\text { eGFR<15 } \\
\mathrm{n}=813\end{array}$ & p Value \\
\hline \multicolumn{7}{|l|}{ Demographics } \\
\hline Age (years) $(n=47716)$ & $60(51-66)$ & $74(65-81)$ & $81(74-86)$ & $83(78-88)$ & $81(73-87)$ & $<0.001$ \\
\hline Female $(n=47716)$ & $27 \%$ & $35 \%$ & $44 \%$ & $50 \%$ & $42 \%$ & $<0.001$ \\
\hline \multicolumn{7}{|l|}{ Risk factors } \\
\hline Hypertension $(n=47702)$ & $36 \%$ & $45 \%$ & $52 \%$ & $57 \%$ & $62 \%$ & $<0.001$ \\
\hline Diabetes mellitus $(n=47704)$ & $21 \%$ & $21 \%$ & $26 \%$ & $35 \%$ & $36 \%$ & $<0.001$ \\
\hline Smoking $(n=47711)$ & $24 \%$ & $11 \%$ & $6 \%$ & $5 \%$ & $8 \%$ & $<0.001$ \\
\hline Alcohol overconsumption $(n=47703)$ & $6 \%$ & $3 \%$ & $1 \%$ & $1 \%$ & $1 \%$ & $<0.001$ \\
\hline \multicolumn{7}{|l|}{ Heart disease } \\
\hline $\begin{array}{l}\text { Previous myocardial infarction } \\
(n=18285)\end{array}$ & $24 \%$ & $29 \%$ & $37 \%$ & $41 \%$ & $37 \%$ & $<0.001$ \\
\hline Ischaemic heart disease $(n=47698)$ & $33 \%$ & $41 \%$ & $50 \%$ & $56 \%$ & $54 \%$ & $<0.001$ \\
\hline Atrial fibrillation/flutter $(n=47702)$ & $32 \%$ & $48 \%$ & $54 \%$ & $52 \%$ & $42 \%$ & $<0.001$ \\
\hline Valvular heart disease $(n=47699)$ & $14 \%$ & $19 \%$ & $23 \%$ & $24 \%$ & $19 \%$ & $<0.001$ \\
\hline Dilated cardiomyopathy ( $n=47698$ ) & $22 \%$ & $12 \%$ & $7 \%$ & $5 \%$ & $5 \%$ & $<0.001$ \\
\hline $\begin{array}{l}\text { Hypertrophic cardiomyopathy } \\
(n=29648)\end{array}$ & $2 \%$ & $2 \%$ & $2 \%$ & $2 \%$ & $2 \%$ & 0.672 \\
\hline \multicolumn{7}{|l|}{ Comorbidity } \\
\hline Previous stroke $(n=18281)$ & $7 \%$ & $12 \%$ & $15 \%$ & $17 \%$ & $19 \%$ & $<0.001$ \\
\hline Pulmonary disease $(n=47$ 704) & $17 \%$ & $17 \%$ & $18 \%$ & $19 \%$ & $18 \%$ & 0.004 \\
\hline \multicolumn{7}{|l|}{ Previous procedures } \\
\hline Revascularisation ( $n=47675)$ & $23 \%$ & $24 \%$ & $25 \%$ & $23 \%$ & $23 \%$ & 0.113 \\
\hline Valve intervention $(n=47703)$ & $5 \%$ & $5 \%$ & $6 \%$ & $6 \%$ & $3 \%$ & 0.372 \\
\hline CRT $(n=47700)$ & $2 \%$ & $2 \%$ & $2 \%$ & $2 \%$ & $2 \%$ & 0.710 \\
\hline \multicolumn{7}{|l|}{ Characterisation of heart failure } \\
\hline Hospitalisation at inclusion $(n=47713)$ & $48 \%$ & $61 \%$ & $70 \%$ & $83 \%$ & $90 \%$ & $<0.001$ \\
\hline New heart failure $(n=18279)$ & $53 \%$ & $43 \%$ & $29 \%$ & $20 \%$ & $20 \%$ & $<0.001$ \\
\hline Heart failure $>6$ month $(n=47254)$ & $32 \%$ & $40 \%$ & $55 \%$ & $65 \%$ & $59 \%$ & $<0.001$ \\
\hline \multicolumn{7}{|l|}{ NYHA class $(n=32848)$} \\
\hline NYHA I $(n=3753)$ & $20 \%$ & $14 \%$ & $8 \%$ & $5 \%$ & $6 \%$ & $<0.001$ \\
\hline NYHA II (n=14 844) & $51 \%$ & $50 \%$ & $42 \%$ & $32 \%$ & $28 \%$ & $<0.001$ \\
\hline NYHA III (n=12 582) & $27 \%$ & $33 \%$ & $44 \%$ & $50 \%$ & $42 \%$ & $<0.001$ \\
\hline NYHA IV $(n=1669)$ & $2 \%$ & $3 \%$ & $6 \%$ & $13 \%$ & $24 \%$ & $<0.001$ \\
\hline \multicolumn{7}{|c|}{ Left ventricular ejection fraction $(n=41369)$} \\
\hline$>50 \%(n=9166)$ & $15 \%$ & $20 \%$ & $25 \%$ & $28 \%$ & $26 \%$ & $<0.001$ \\
\hline $40-49 \%(n=8566)$ & $20 \%$ & $21 \%$ & $20 \%$ & $20 \%$ & $21 \%$ & 0.508 \\
\hline $30-39 \%(n=11323)$ & $29 \%$ & $28 \%$ & $26 \%$ & $25 \%$ & $27 \%$ & $<0.001$ \\
\hline$<30 \%(n=12314)$ & $36 \%$ & $31 \%$ & $28 \%$ & $28 \%$ & $26 \%$ & $<0.001$ \\
\hline
\end{tabular}

Values are proportion or median and IQR.

CRT, cardiac resynchronisation therapy; NYHA, New York Heart Association.

variables in model 2, the association between eGFR strata and mortality was further somewhat weakened, but still significant. When adjusting for differences in medical treatment in model 3 , the association between eGFR strata and mortality remained unchanged.

\section{DISCUSSION}

The present study has several important findings. First, kidney function is indeed strongly associated with short and long-term mortality in heart failure patients. In hospitalised patients, the inhospital mortality increased from $2 \%$ in those with normal kidney function (eGFR >90) to $30 \%$ in those with ESRD $($ eGFR $<15)$. For 5 -year mortality, this cumulative probability of death was above $60 \%$ in those with moderate kidney dysfunction and above $80 \%$ in patients with severe kidney dysfunction. Second, this strong association with outcome was evident in all age groups regardless of NYHA class, duration of heart failure, haemoglobin level and presence or absence of diabetes mellitus. Third, after a stepwise adjustment for differences in baseline data, aetiology, and severity of heart disease and treatment, the strong association remained.

Damman et $a \hat{l}$ has recently, in a meta-analysis including more than 1 million patients, clearly demonstrated the strong association between kidney function and outcome.

Our study is so far the largest and most extensively covariate-adjusted cohort study on the association between kidney dysfunction and outcome in an unselected heart failure population. The size of the study and the long-term follow-up allowed us to examine the 


\begin{tabular}{|c|c|c|c|c|c|c|}
\hline & $\begin{array}{l}\text { eGFR } \geq 90 \\
n=5251\end{array}$ & $\begin{array}{l}\text { eGFR } 60-89 \\
n=18240\end{array}$ & $\begin{array}{l}\text { eGFR } 30-59 \\
n=19160\end{array}$ & $\begin{array}{l}\text { eGFR 15-29 } \\
n=4252\end{array}$ & $\begin{array}{l}\text { eGFR<15 } \\
\mathrm{n}=813\end{array}$ & p Value \\
\hline \multicolumn{7}{|l|}{ Physical signs } \\
\hline Heart rate $(n=36087)$ & $72(64-84)$ & $72(63-83)$ & $72(64-83)$ & $74(64-84)$ & $76(67-90)$ & $<0.001$ \\
\hline Blood pressure systolic $(n=47142)$ & $120(110-140)$ & $128(112-140)$ & $125(110-140)$ & $124(110-140)$ & $130(110-150)$ & $<0.001$ \\
\hline Blood pressure diastolic $(n=47081)$ & $75(68-80)$ & $74(65-80)$ & $70(61-80)$ & $70(60-80)$ & $70(60-80)$ & $<0.001$ \\
\hline BMI $(n=23540)$ & $27(24-31)$ & $26(23-30)$ & $26(23-29)$ & $26(23-29)$ & $26(23-29)$ & $<0.001$ \\
\hline \multicolumn{7}{|l|}{ ECG } \\
\hline Non-sinus rhythm(n=47 701) & $29 \%$ & $45 \%$ & $54 \%$ & $52 \%$ & $42 \%$ & $<0.001$ \\
\hline Left bundle branch block $(n=43550)$ & $15 \%$ & $16 \%$ & $17 \%$ & $17 \%$ & $14 \%$ & 0.006 \\
\hline QRS-width, msek (n=38 098) & $100(90-116)$ & $102(90-124)$ & $104(90-128)$ & $104(90-130)$ & $104(92-128)$ & $<0.001$ \\
\hline \multicolumn{7}{|l|}{$\mathrm{Lab}$} \\
\hline Haemoglobin $(n=47705)$ & $139(127-150)$ & $135(123-147)$ & $129(117-141)$ & $120(110-131)$ & $112(103-123)$ & $<0.001$ \\
\hline Creatinine $(n=47716)$ & $67(58-75)$ & $83(72-93)$ & $116(102-133)$ & $191(163-220)$ & $382(325-492)$ & $<0.001$ \\
\hline Potassium ( $n=27713)$ & $4,1(3,8-4,4)$ & $4,1(3,8-4,4)$ & $4,2(3,9-4,6)$ & $4,2(3,9-4,6)$ & $4,5(4,0-5,0)$ & $<0.001$ \\
\hline NT-proBNP (n=13 859) & $1390(494-3366)$ & $2320(1090-4800)$ & $3800(1780-7826)$ & 7880 (3357-16 862) & $21000(1260-35000)$ & $<0.001$ \\
\hline \multicolumn{7}{|l|}{ Medication } \\
\hline $\operatorname{ACEI}(n=47701)$ & $76 \%$ & $69 \%$ & $58 \%$ & $38 \%$ & $20 \%$ & $<0.001$ \\
\hline$>50 \%$ of target dose $(n=29412)$ & $80 \%$ & $77 \%$ & $72 \%$ & $55 \%$ & $49 \%$ & $<0.001$ \\
\hline ARB $(n=47694)$ & $16 \%$ & $29 \%$ & $22 \%$ & $20 \%$ & $16 \%$ & $<0.001$ \\
\hline$>50 \%$ of target dose $(n=9529)$ & $63 \%$ & $56 \%$ & $46 \%$ & $29 \%$ & $36 \%$ & $<0.001$ \\
\hline$\beta$-blocker $(n=47700)$ & $88 \%$ & $85 \%$ & $84 \%$ & $81 \%$ & $77 \%$ & $<0.001$ \\
\hline$>50 \%$ of target dose $(n=40033)$ & $66 \%$ & $64 \%$ & $62 \%$ & $59 \%$ & $58 \%$ & $<0.001$ \\
\hline Aldosteronblocker $(n=47701)$ & $28 \%$ & $29 \%$ & $30 \%$ & $22 \%$ & $11 \%$ & $<0.001$ \\
\hline Digitalis $(n=47700)$ & $16 \%$ & $19 \%$ & $17 \%$ & $10 \%$ & $5 \%$ & $<0.001$ \\
\hline Statins $(n=47701)$ & $44 \%$ & $44 \%$ & $42 \%$ & $37 \%$ & $35 \%$ & $<0.001$ \\
\hline Nitrates $(n=47700)$ & $6 \%$ & $13 \%$ & $21 \%$ & $27 \%$ & $25 \%$ & $<0.001$ \\
\hline Anticoagulant $(n=47701)$ & $33 \%$ & $39 \%$ & $38 \%$ & $29 \%$ & $17 \%$ & $<0.001$ \\
\hline Aspirin $(n=47700)$ & $45 \%$ & $49 \%$ & $52 \%$ & $56 \%$ & $57 \%$ & $<0.001$ \\
\hline
\end{tabular}




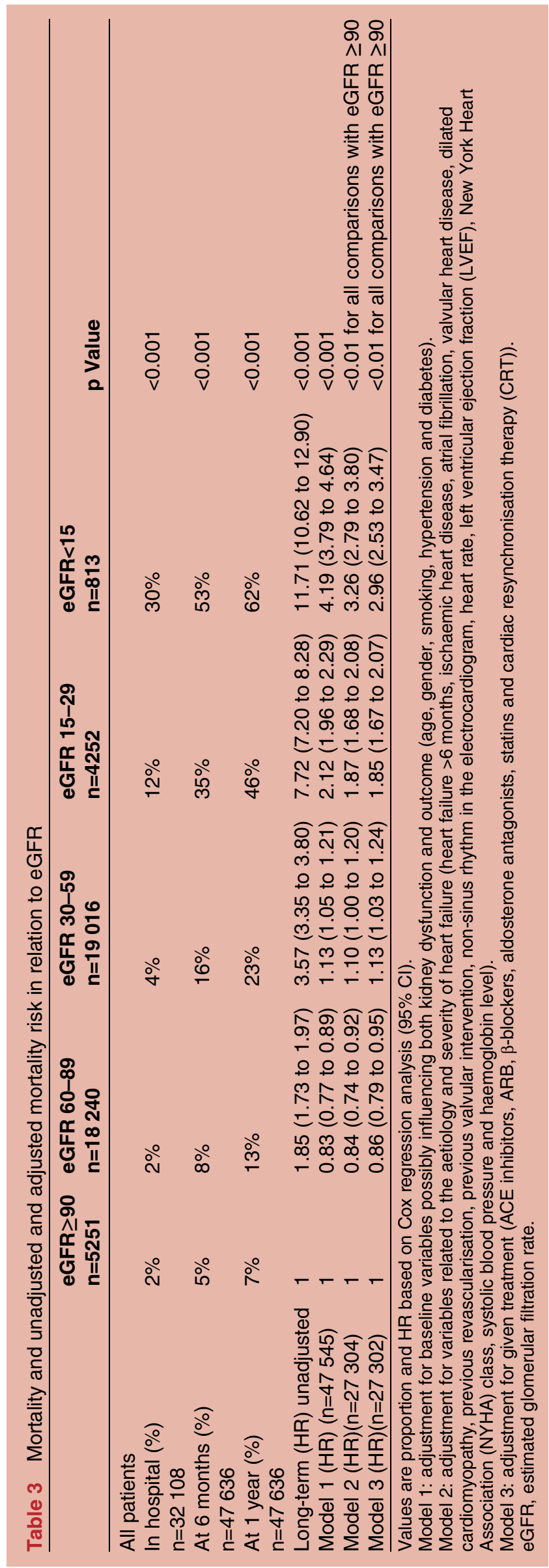

whole spectrum of kidney disease and its association with subsequent mortality. It was also possible to examine the prognostic influence of different degrees of kidney dysfunction in important subgroups and it provides us with important findings regarding these patients' risk profile.

In our registry, half of the patients had at least a moderate kidney dysfunction (eGFR $<60 \mathrm{~mL} / \mathrm{min}$ ), which is in line with earlier observations. ${ }^{17}$ For lower kidney function, the patients were older and more often had hypertension, diabetes mellitus and other cardiovascular disease as seen in other studies. ${ }^{18}$ They also more often had a long duration of disease and more severe NYHA class, in line with other previous studies. ${ }^{19}$

The higher mortality in patients with kidney dysfunction seen in the present study, compared to several previous studies, ${ }^{1320}$ is probably explained by the unselected nature of the material. Since this is registry data collected from the clinical routine, patients were considerable older (median age of 77 years) than in the other studies. ${ }^{12}{ }^{21}$ However, even though the mortality was lower in patients under 65 years of age, there was still a high 5-year mortality, well in line with earlier results in more selected population. ${ }^{22}$

The associations between kidney function and outcome was similar regardless of age, NYHA class, duration of heart failure, haemoglobin level and presence or absence of diabetes. Notably, when kidney function was known, presence of diabetes had very little effect on mortality (figure 2A). Furthermore, in patients with at least severe kidney dysfunction, the mortality was very high and the additive prognostic value of NYHA class and haemoglobin level limited.

There are several possible reasons for the association between kidney dysfunction and outcome in the present population. The worse prognosis can at least partially be explained by a higher prevalence of traditional risk factors such as higher age, hypertension and diabetes. Though, even after adjustments for these risk factors, impaired kidney function remained strongly associated with mortality confirms results from earlier observations indicating that GFR is an independent predictor itself for outcome. ${ }^{18}$

Kidney dysfunction may be secondary to venous congestion, forward failure, renin-angiotensin-aldosterone system (RAAS) stimulation and sympathetic activation in heart failure, but may also suppress the cardiac function further. In the present study, adjusting for factors related to aetiology and severity of heart failure reduced the association between the degree of kidney dysfunction and outcome, but to a limited extent. This can be explained by residual confounding that arises from unmeasured or dichotomised variables. However, it mav also indicate that factors that are strongly related to kidney dysfunction, such as activation of neurohormones, immunological activation, inflammation and uraemia, are of crucial importance for outcome as these affect vital organs. ${ }^{23}$ 
Figure 2 (A) 1-year mortality in relation to estimated glomerular filtration rate (eGFR), age $(n=47636)$ and presence of diabetes mellitus $(n=47624)$. (B) 1-year mortality in relation to eGFR and New York Heart Association class $(n=32811)$ and haemoglobin level ( $n=47626)$. $\mathrm{DM}$, diabetes mellitus; y, years.

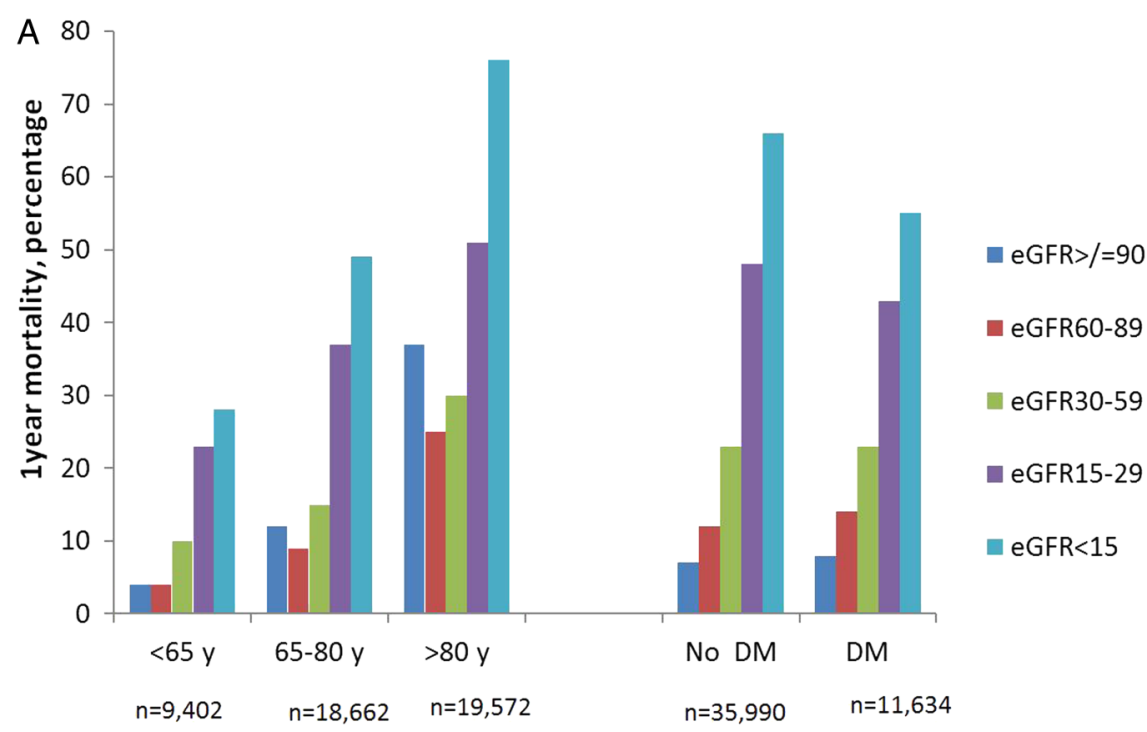

$\mathrm{y}=$ years, $\mathrm{DM}=$ diabetes mellitus, eGFR $(\mathrm{ml} / \mathrm{min} / 1,73 \mathrm{~m} 2)$

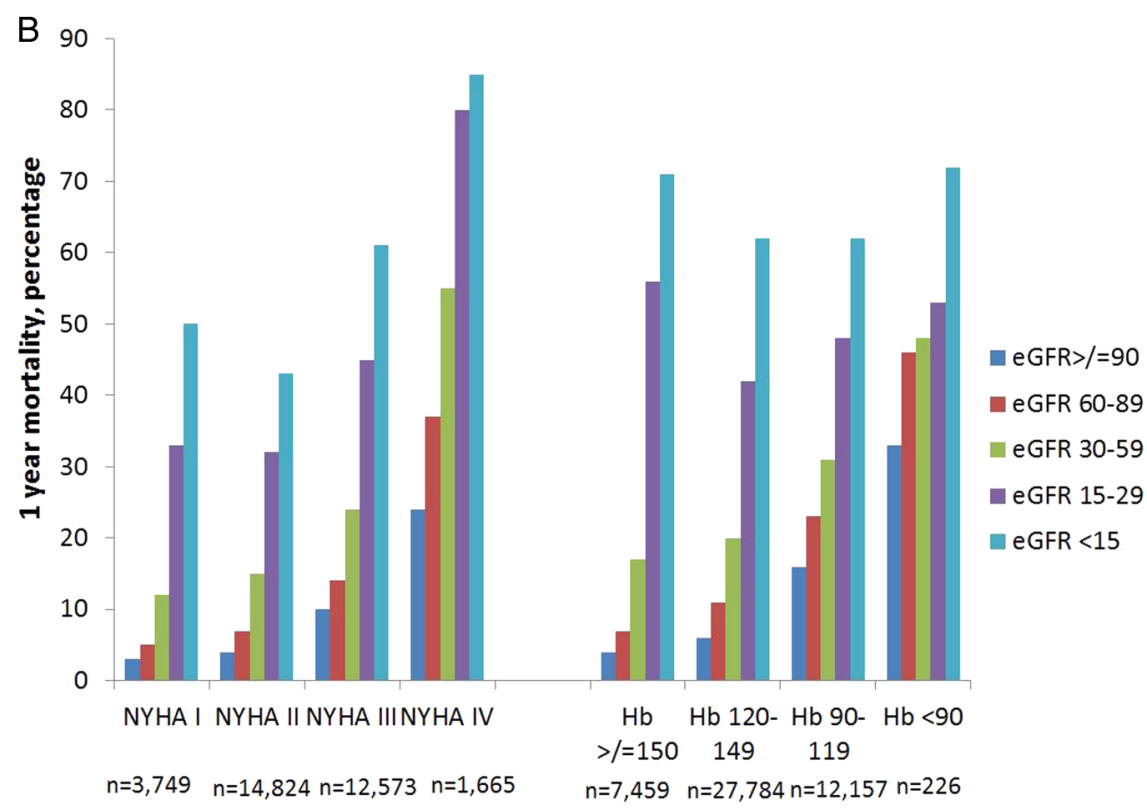

NYHA $=$ New York Heart Association, $\mathrm{Hb}=$ hemoglobin $(\mathrm{g} / \mathrm{l}), \mathrm{eGFR}(\mathrm{ml} / \mathrm{min} / 1,73 \mathrm{~m} 2)$
Several studies have shown that patients with cardiovascular disease and CKD receive less of guideline recommended treatments, partly due to lack of evidence from clinical trials and concerns regarding drug toxicity. ${ }^{13}$ In the present study, differences between eGFR strata regarding the use of antithrombotic treatment, statins and $\beta$-blockers were rather small despite the large differences in age distributions. Patients with low eGFR were less often treated with ACE inhibitors and less often reached target doses of RAAS blockade. However, though these drugs are believed to be beneficial even with severely depressed kidney function caution is recommended when treating patients with CKD. ${ }^{7} 2425$ When adjusting for treatment in our study, the association between kidney function and outcome remained unchanged. This may indicate that under treatment is not an important cause of the association between kidney dysfunction and outcome.

There are limitations to this study. This is a registry that reflects clinical practice. There may be a certain selection of patients, as some patients may not have been included in the register because of frailty, comorbidity, or other reasons. This may affect the generalisability of our study. However, compared to many other studies, our study sample should be considered as fairly unselective, closely reflecting the everyday clinical practice. Patients are included according to clinicianjudged heart failure, which due to the heterogeneity of the disease and difficulty in establishing the correct diagnoses is likely to contain a certain degree of 

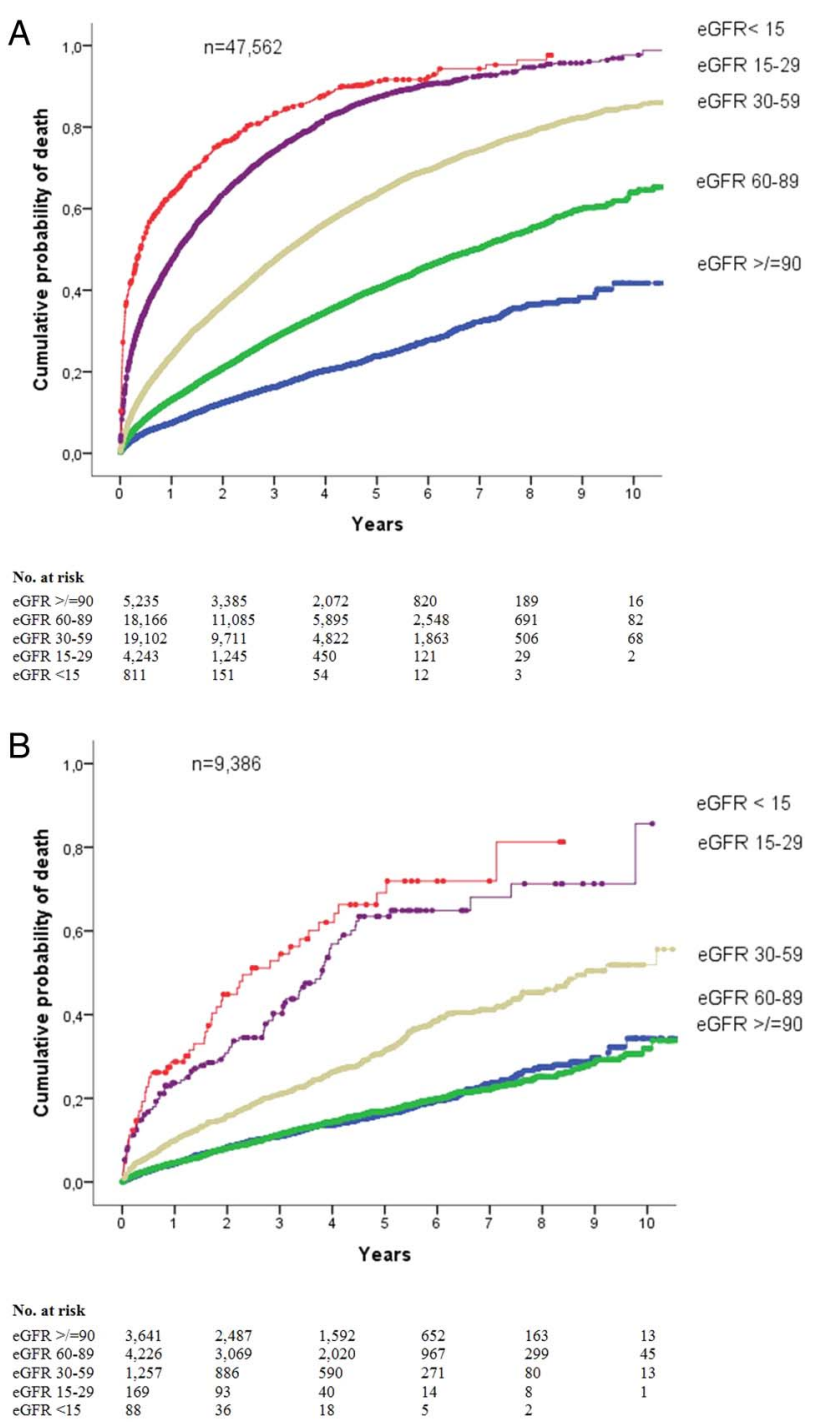

Figure 3 (A) Mortality in patients with heart failure and different estimated glomerular filtration rate (eGFR) strata, crude survival assessed by Kaplan-Meier analysis, log rank $p<0.001$. (B) Mortality in patients under 65 years with heart failure and different GFR strata, crude survival assessed by Kaplan-Meier analysis, log rank $\mathrm{p}<0.001$.

misclassification. The register has no information of creatinine over time and no data regarding blood urea nitrogen. Dialysis status was not collected as part of the SwedeHF and hence this cannot be reported; however, in an earlier SwedeHF study with linkage to the Swedish Patient Registry, dialysis was used in about $1 \%$ of the patients. ${ }^{26}$ In spite of adjusting for a large number of confounders, residual confounding may still exist due to unmeasured factors that could not be adjusted for.

In conclusion, this large and extensively covariateadjusted study from a nationwide and generalisable registry shows that kidney dysfunction is strongly associated with short-term and long-term outcome in patients with heart failure. These findings emphasise the importance of close follow-up and kidney preservation in patients with heart failure and kidney disease.
Acknowledgements The authors would like to thank the steering group of the Swedish Heart Failure Registry, and all the hospitals and outpatient clinics that report to the registry.

Contributors IL, KS and TJ have worked with all parts of the study. LHL, $\mathrm{IH}$ and UD were involved with the planning of the study, analysing and interpretation of the data, and the revising of the manuscript. All authors have approved the manuscript and its submission. There has been no relationship with the industry.

Funding This work was supported by the Swedish Foundation for Strategic Research, the Swedish Heart and Lung Foundation and the Stockholm County Council (ALF project). KS was supported by the Stockholm County Council (clinical post-doctoral appointment).

Competing interests UD reports grants from Astra Zeneca Inc, other from Novartis Inc, outside the submitted work. LHL has received grants to his institution from Boston Scientific and Astra Zeneca, and honorary for lecturing from Novartis. TJ has received honorary from Astra Zeneca for lecturing and consulting. KS has received lecture honorary from Astra Zeneca and Aspen.

Ethics approval Ethics Committee of Stockholm.

Provenance and peer review Not commissioned; externally peer reviewed.

Data sharing statement No additional data are available.

Open Access This is an Open Access article distributed in accordance with the Creative Commons Attribution Non Commercial (CC BY-NC 4.0) license, which permits others to distribute, remix, adapt, build upon this work noncommercially, and license their derivative works on different terms, provided the original work is properly cited and the use is non-commercial. See: http:// creativecommons.org/licenses/by-nc/4.0/

\section{REFERENCES}

1. Cleland J. The EuroHeart Failure survey programme-a survey on the quality of care among patients with heart failure in Europe Part 1 patient characteristics and diagnosis. Eur Heart J 2003;24:442-63.

2. Pocock SJ, Wang D, Pfeffer MA, et al. Predictors of mortality and morbidity in patients with chronic heart failure. Eur Heart $J$ 2006;27:65-75.

3. Damman K, Valente MA, Voors AA, et al. Renal impairment worsening renal function, and outcome in patients with heart failure: an updated meta-analysis. Eur Heart J 2014;35:455-69.

4. Ronco C, Haapio M, House AA, et al. Cardiorenal syndrome. J Am Coll Cardiol 2008;52:1527-39.

5. Metra M, Cotter G, Gheorghiade M, et al. The role of the kidney in heart failure. Eur Heart J 2012;33:2135-42.

6. Damman K, Voors AA, Navis G, et al. The cardiorenal syndrome in heart failure. Prog Cardiovasc Dis 2011:54:144-53.

7. Dries DL, Exner DV, Domanski MJ, et al. The prognostic implications of renal insufficiency in asymptomatic and symptomatic patients with left ventricular systolic dysfunction. J Am Coll Cardiol 2000;35:681-9.

8. Hillege HL, Girbes AR, de Kam PJ, et al. Renal function, neurohormonal activation, and survival in patients with chronic heart failure. Circulation 2000;102:203-10.

9. Herzog CA, Muster HA, Li S, et al. Impact of congestive heart failure, chronic kidney disease, and anemia on survival in the Medicare population. J Card Fail 2004;10:467-72.

10. Kao DP, Kreso E, Fonarow GC, et al. Characteristics and outcomes among heart failure patients with anemia and renal insufficiency with and without blood transfusions (public discharge data from California 2000-2006). Am J Cardiol 2011;107:69-73.

11. Velavan P, Khan NK, Goode K, et al. Predictors of short term mortality in heart failure-insights from the Euro Heart Failure survey. Int J Cardiol 2010;138:63-9.

12. Harjola VP, Follath F, Nieminen MS, et al. Characteristics, outcomes, and predictors of mortality at 3 months and 1 year in patients hospitalized for acute heart failure. Eur $J$ Heart Fail 2010;12:239-48.

13. Heywood JT, Fonarow GC, Costanzo MR, et al. High prevalence of renal dysfunction and its impact on outcome in 118,465 patients hospitalized with acute decompensated heart failure: a report from the ADHERE database. J Card Fail 2007;13:422-30.

14. Jonsson $A$, Edner $M$, Alehagen $U$, et al. Heart failure registry: a valuable tool for improving the management of patients with heart failure. Eur J Heart Fail 2010;12:25-31. 
15. Valente MA, Hillege HL, Navis G, et al. The Chronic Kidney Disease Epidemiology Collaboration equation outperforms the Modification of Diet in Renal Disease equation for estimating glomerular filtration rate in chronic systolic heart failure. Eur J Heart Fail 2014;16:86-94.

16. Kidney Disease: Improving Global Outcomes (KDIGO) CKD Work Group. KDIGO 2012 Clinical Practice Guideline for evaluation and management of chronic kidney disease. Kidney Int Suppl 2013;3:1-150.

17. Blair JE, Pang PS, Schrier RW, et al. Changes in renal function during hospitalization and soon after discharge in patients admitted for worsening heart failure in the placebo group of the EVEREST trial. Eur Heart J 2011;32:2563-72.

18. Go AS, Chertow GM, Fan D, et al. Chronic kidney disease and the risks of death, cardiovascular events, and hospitalization. $N$ Engl $J$ Med 2004;351:1296-305.

19. Hillege HL, Nitsch D, Pfeffer MA, et al. Renal function as a predictor of outcome in a broad spectrum of patients with heart failure. Circulation 2006:113:671-8.

20. McClellan WM. Anemia and renal insufficiency are independent risk factors for death among patients with congestive heart failure admitted to community hospitals: a population-based study. J Am Soc Nephrol 2002;13:1928-36.
21. Damman K, Voors AA, Hillege HL, et al. Congestion in chronic systolic heart failure is related to renal dysfunction and increased mortality. Eur J Heart Fail 2010;12:974-82.

22. McAlister FA, Ezekowitz J, Tonelli M, et al. Renal insufficiency and heart failure: prognostic and therapeutic implications from a prospective cohort study. Circulation 2004;109:1004-9.

23. Di Lullo L House A, Gorini A, et al. Chronic kidney disease and cardiovascular complications. Heart Fail Rev 2015;20:259-72.

24. Anand IS, Bishu K, Rector TS, et al. Proteinuria, chronic kidney disease, and the effect of an angiotensin receptor blocker in addition to an angiotensin-converting enzyme inhibitor in patients with moderate to severe heart failure. Circulation 2009;120: 1577-84.

25. McMurray JJ, Adamopoulos S, Anker SD, et al. ESC guidelines for the diagnosis and treatment of acute and chronic heart failure 2012: The Task Force for the Diagnosis and Treatment of Acute and Chronic Heart Failure 2012 of the European Society of Cardiology. Developed in collaboration with the Heart Failure Association (HFA) of the ESC. Eur J Heart Fail 2012;14:803-69.

26. Lund LH, Benson L, Dahlstrom U, et al. Association between use of beta-blockers and outcomes in patients with heart failure and preserved ejection fraction. JAMA 2014;312:2008-18. 